\title{
Monetary policy responses to the exchange rate: Empirical evidence from the $\mathrm{ECB}^{\grave{2}}$
}

\author{
İshak Demir \\ Department of Economics, Bilkent University, 06800 Ankara, Turkey
}

\section{A R T I C L E I N F O}

\section{Article history:}

Accepted 20 February 2014

Available online 18 March 2014

\section{JEL classification:}

E44

E52

G12

\section{Keywords:}

Monetary policy

Exchange rates

Identification through heteroscedasticity

European Central Bank

Monetary policy reaction

\begin{abstract}
A B S T R A C T
The exchange rate is an important part of the transmission mechanism in the determination of monetary policy because movements in the exchange rate have significant effect on the macroeconomy. It can be difficult to measure the reaction of monetary policy to the movements of the exchange rate, due to the simultaneous response of monetary policy to the exchange rate and the possibility that both variables respond to several other variables. This study addresses these problems by using an identification method based on the heteroscedasticity in the high-frequency data. The results in this paper suggest that the ECB systematically responds to exchange rate movements but that quantitative effects are small. Such a significant but small reaction coefficient seems consistent with the hypothesis that the central banks do not target the fluctuations in the exchange rate but consider them only to the extent they impact on the expected inflation and output path.
\end{abstract}

(C) 2014 Elsevier B.V. All rights reserved.
“... it is clearly not opportune to introduce asset prices into a monetary policy rule the central bank should commit to or in the central bank's reaction function." Jean-Claude Trichet (2002).

\section{Introduction}

There are three main channels through which the exchange rate affects the macroeconomy. Appreciation lowers real GDP because of expenditure switching, and further, it lowers inflation because the price of imported goods does not increase as rapidly with the appreciation of the currency (Taylor, 2001). Secondly, changes in the exchange rate also generate wealth effects that may have a significant impact on consumption and investment, both of which are components of aggregate demand. Because of households' inter-temporal smoothing behavior, a direct decrease in net wealth may lead to a drop in consumption. Lastly, depreciation can increase the value of collateral which may reduce agents' external financing constraints and enhance final spending in accordance with the "broad credit channel".

Because of these important impacts of the exchange rate on aggregate demand, output and inflation, which are components of policy rule, there may be a relationship between exchange rates and monetary

\footnotetext{
is For useful comments and valuable feedback I thank Refet Gurkaynak, Bedri Kamil Onur Tas, Kivilcim Metin Ozcan and seminar participants at the Bilkent University.

E-mail address: i.demir@mail.bbk.ac.uk.
}

policy rules. The main objective of this paper is to measure the response of monetary policy to the exchange rate in the Euro area and try to determine the role of the exchange rate in monetary policy.

Although the monetary policy response to exchange rates has largely been studied in the empirical literature, there are some difficulties in measuring this effect. To begin with, while monetary policy is affected by changes in exchange rate, the exchange rate also responds to the changes in the monetary policy; i.e. there is a simultaneous response of both variables to each other, so, the direction of causality is difficult to establish. Moreover, there are other unobservable common factors affecting both short term interest rates and exchange rates, such as macroeconomic news and change in the risk preference. Hence, measurement is complicated due to the endogeneity problem and the possibility of relevant variables being omitted.

There is considerable empirical literature on the exchange rate in a policy rule. However, general empirical studies ignore the endogeneity problem and eliminate numerous factors affecting interest rates and exchange rates. Most of them use the least square, two stages least square, VAR and IV approaches to estimate the response of interest rates. But these approaches cannot appropriately solve the problems mentioned above. Least square results are strongly biased; there are no obvious restrictions to identify monetary policy shocks in the VAR framework; and lastly, it is hard to find a proper instrument which affects the exchange rate without affecting interest rates. In this study, to address these problems, we apply a new identification approach developed by Rigobon (2003a), which argues that the response of monetary policy is based 
on the heteroscedasticity of exchange rate shocks. In particular shift in the importance of the exchange rate shocks relative to the monetary policy shocks thereby estimated changes in variance-covariance matrix between shocks make measure the responsiveness of monetary policy to exchange rate possible. Heteroscedasticity based identification is a relatively new method and this paper presents the first study to employ this approach to measure policy reactions to the exchange rate movements for ECB data.

The impact of asset prices on the conduct of monetary policy debates has increased over the last decade. Taylor (2001) argues that a monetary policy rule that reacts directly to the exchange rate, as well as to inflation and output, sometimes works worse than policy rules that do not react directly to the exchange rate. However, Bernanke and Gertler (1999, 2001) argue that monetary policy should react to asset price movements only to the extent warranted by their impact on expected inflation. On similar lines, Rigobon and Sack (2003) find that the Federal Reserve reacts significantly to changes in the stock market. Their findings suggest that policy-makers are reacting to asset price movements to the extent warranted by their implications for the economy. In the context of discussing the impact of asset prices on monetary policy, Jean-Claude Trichet, governor of the ECB from 2003 to 2011, stated that financial indicators (stock prices, housing prices, exchange rates) are also analyzed in depth and they are assessed in the context of maintaining price stability over the medium term: the ECB does not react to their signals unless price stability is endangered. Conversely, the empirical findings of this paper indicate that the ECB responds systematically to the exchange rate movements and the reaction coefficient is significantly negative but small. Since the estimated policy reaction coefficient is within reasonable range of the magnitude, it appears that the ECB reacts to exchange rate fluctuations only to offset the expected impact of exchange rate shocks on inflation and output.

The paper proceeds as follows. Section 2 briefly describes the relevant studies in the literature and the contribution of this paper. Section 3 discusses the problems of simultaneous equations and omitted variables and demonstrates why other widely used identification methods are inappropriate in this context. Also, this section describes the identification approach based on the heteroscedasticity of exchange rate shocks. Section 4 gives information about the data and contains the empirical results. It also argues the policy implications of empirical results. Section 5 concludes with a summary.

\section{Background}

The movements in the exchange rate in monetary policy rules are discussed in the theoretical and empirical literature. Ball $(1999,2002)$ argues for the role of exchange rate in inflation targeting frameworks for closed and open economies. He found that pure inflation targeting without considering the exchange rate is dangerous, because it causes large fluctuations in output. The effect of exchange rates on inflation through import prices is the fastest channel and so inflation targeting implies that it is used aggressively. However, large shifts in the exchange rate create oscillations in output. Ball found that, holding the standard deviation of output relative to potential output constant (at $1.4 \%)$, the interest-rate rule that reacts to the exchange rate as well as to output and inflation reduces the standard deviation of the inflation rate around the inflation target from $2.0 \%$ to $1.9 \%$ (Ball, 1999 p. 134) compared with a rule that reacts only to inflation and output. But this improvement is small. He suggests that policy rules in open economies should be modified to include information about the exchange rate. He uses a policy instrument - namely Monetary Condition Index (MCI), a weighted average of the interest rate and the exchange rate. Central banks should choose "long-run inflation targeting": a measure of inflation adjusted to filter out the effects of exchange rate.

Taylor (2001) examines the exchange rate as a candidate for a monetary policy rule for the ECB in the form suggested in Ball's (1999) studies. He argues that a monetary policy rule which responds directly to the exchange rate, as well as to inflation and output, sometimes works worse than policy rules without reference to the exchange rate. In his 2002 study, however, Taylor indicates that the monetary policy in open economies is different from the policy in closed economies. Central banks seem averse to significant variability in exchange rates. They should target a measure of inflation that removes the transitory effects of exchange rate fluctuations as Ball (2002) suggests and they should also contain the exchange rate in their policy rules.

On the other hand, the results of empirical studies focusing on policy rules with exchange rates are quite controversial with theoretical studies mentioned above. Clarida et al. (1998) show that monetary policy responds to the exchange rate in industrial countries, but the magnitude of the monetary policy reaction is small. Along the same lines, Osawa (2006) estimates monetary policy reaction functions to examine whether monetary policy responds to fluctuations in the exchange rate under the inflation-targeting regimes in Korea, Thailand and the Philippines using two stage least squares and ordinary least squares (OLS). He finds no evidence that monetary policy reacts to the exchange rate. Inclusion of the Asian financial crisis period overestimates the monetary policy reaction because exchange rate and interest rate are fluctuated widely during the crisis period. For the same countries, Sek (2008) apply a GMM and structural VAR to investigate the relationship between exchange rates and monetary policy. The results of these approaches are consistent with each other, i.e. the monetary policy reactions in Philippines and Korea do not response significantly to exchange rate directly. But they only find a strong reaction of policy in Thailand to exchange rate fluctuations in the pre-crisis period. The results in these empirical papers are in accord with the results in Ball (1999) and Taylor (2001).

On the other hand, Filosa (2001) finds that many central banks in emerging countries react strongly to exchange rate movements, although changes in the monetary policy regime make it difficult to assess the relative importance placed by countries on inflation control and external equilibrium. Mohanty and Klau (2005) also find a strong response of monetary policy to exchange rates for Asian countries by focusing on quarterly data between 1995 and 2002. Lastly, Frömmel and Schobert (2006) estimate a Taylor rule for six European countries. They point out that the exchange rate plays an important role in the monetary policy during the fixed exchange rate regime periods. However, this impact disappears after the introduction of flexible regimes.

Most of the empirical studies in the literature do not address the endogeneity problem and the numerous factors affecting interest rates and exchange rates simultaneously. Therefore, they cannot appropriately separate out the response of monetary policy to the exchange rate. This paper aims to come up with unbiased estimates with the heteroscedasticity based identification approach.

\section{Statement of the problem and methodology}

In this paper, in order to overcome endogeneity between exchange rates and interest rates, we use an identification method suggested by Rigobon (2003a). This method relies on the heteroscedasticity in interest rates and exchange rates to identify the monetary policy reaction to the exchange rate. Shifts in importance of exchange rate shocks relative to monetary policy shocks change the covariance between the exchange rate and policy rate. It allows us to identify the interest rate reaction to fluctuations in exchange rate based on changes in covariance.

The data suggest that shifts in the variance of shocks affect the correlation between changes in interest rates and exchange rates. Fig. 1 shows the correlation between daily changes in the exchange rate and daily changes in the short-term interest rate. Note that the correlation varies but mostly becomes negative during periods in which the volatility of exchange rates increased.

\footnotetext{
${ }^{1}$ The equations used in this section are inspired by RS (2003b).
} 


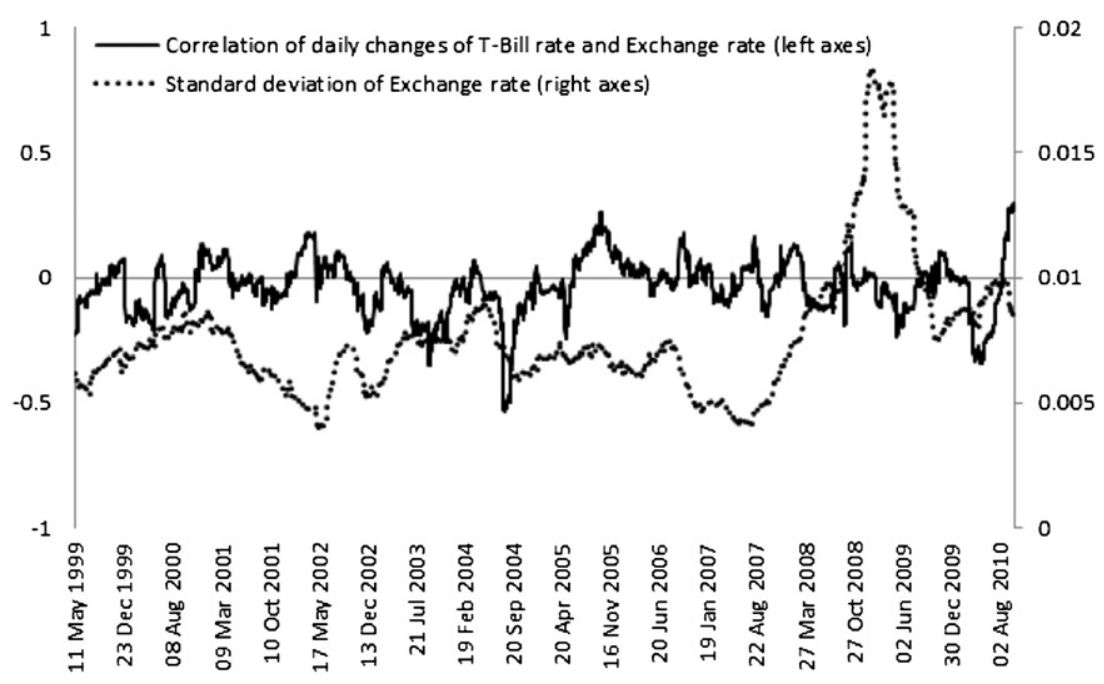

Fig. 1. Comovements in exchange rate and interest rates.

A VAR model, which includes unobserved shocks that affect the interest rate and exchange rate, is conducted as in Rigobon and Sack (2003). The dynamic structural equations for the short-term interest rate and the exchange rate are written as follows:

$i_{t}=\beta e_{t}+\theta x_{t}+\gamma z_{t}+\varepsilon_{t}$

$e_{t}=\alpha i_{t}+\phi x_{t}+z_{t}+\eta_{t}$

where $i_{t}$ is the short-term interest rate, $e_{t}$ is the exchange rate and $z_{t}$ is the unobserved variables. ${ }^{2}$ The variable $x_{t}$ captures observable shocks and $z_{t}$ summarizes some unobserved shocks affecting the exchange rate and the interest rate such as changes in risk preference and liquidity shocks. Eq. (1) is the high frequency monetary policy reaction function for ECB. ${ }^{3} \mathrm{Eq}$. (2) represents the exchange rate equation, which measures the response of the exchange rate to the interest rate and other shocks. $\varepsilon_{t}$ is the monetary policy shock, and $\eta_{t}$ is the exchange rate shock. The residuals $\varepsilon_{t}, \eta_{t}$ and unobserved shock $z_{t}$ are assumed to be serially uncorrelated and to be uncorrelated with each other.

Eqs. (1) and (2) cannot be estimated directly, because of the endogeneity between $i_{t}$ and $e_{t}$ and because of unobservable variable $z_{t}$. Only the following reduced form of Eqs. (1) and (2) can be estimated:

$$
\left(\begin{array}{c}
i_{t} \\
e_{t}
\end{array}\right)=\Phi x_{t}+\left(\begin{array}{c}
\nu_{t}^{i} \\
\nu_{t}^{e}
\end{array}\right)
$$

where the reduced form residuals are given by

$\nu_{t}^{i}=\frac{1}{1-\alpha \beta}\left[(\beta+\gamma) z_{t}+\beta \eta_{t}+\varepsilon_{t}\right]$

$\nu_{t}^{e}=\frac{1}{1-\alpha \beta}\left[(1+\alpha \gamma) z_{t}+\eta_{t}+\alpha \varepsilon_{t}\right]$

The covariance matrix of the reduced form residuals is

$$
\begin{aligned}
& \Omega=E\left[\left[i_{t} e_{t}\right]^{\prime}\left[i_{t} e_{t}\right]\right] \\
& \Omega=\frac{1}{(1-\alpha \beta)^{2}}\left[\begin{array}{cc}
(\beta+\gamma)^{2} \sigma_{z}^{2}+\beta^{2} \sigma_{\eta}^{2}+\sigma_{\varepsilon}^{2} & (1+\alpha \gamma)(\beta+\gamma) \sigma_{z}^{2}+\beta \sigma_{\eta}^{2}+\alpha \sigma_{\varepsilon}^{2} \\
. & (1+\alpha \gamma)^{2} \sigma_{z}^{2}+\sigma_{\eta}^{2}+\alpha^{2} \sigma_{\varepsilon}^{2}
\end{array}\right] .
\end{aligned}
$$

\footnotetext{
2 The coefficient on $z_{t}$ in the exchange rate equation normalized to 1 .

${ }^{3}$ When $x_{t}$ contains inflation and output gap as observable variables, Eq. (1) would be a sort of modified Taylor rule.
}

The covariance matrix only provides three moments-two variances and a covariance while in matrix $\Omega$ but there are six unknowns: $\alpha, \beta, \gamma$, $\sigma_{z}^{2}, \sigma_{\eta}^{2}$ and $\sigma_{\varepsilon}^{2}$. Hence, these restrictions are not enough to achieve identification and recover the structural form parameters. Heteroscedasticity in the reduced form residuals provides additional restrictions to the system represented by (5). A shift to a regime with a different covariance matrix provides three new equations and the new regime also adds three unknown parameters $\sigma_{z}^{2}, \sigma_{\eta}^{2}$ and $\sigma_{\varepsilon}^{2}$.

Within this framework, assuming that the monetary policy shocks $\varepsilon_{t}$ are homoscedastic ensure an identification. As is well known, the general characteristic of macroeconomic data is heteroscedastic and monetary policy shocks are heteroscedastic as well. Since our subsample stands for the non-policy dates (days immediately preceding the monetary policy committee meeting days), we assume that monetary policy shocks $\varepsilon_{t}$, are homoscedastic across regimes. The assumption of constant monetary policy shocks is not very restrictive, because of the fact that the variance of the interest rate consists of varying $\sigma_{\eta}^{2}$ and $\sigma_{z}^{2}$. This implies $i_{t}$ is not homoscedastic and it is based on varying unobserved shocks and exchange rate shocks through different regimes.

Under the assumption of homoscedastic policy shocks, a shift in the covariance matrix provides three new equations but only two new unknown parameters. Moreover, we assume: $\alpha, \beta$ and $\gamma$ are stable across the covariance regimes. ${ }^{4}$ Under these assumptions at least three different regimes for the covariance matrix are required to identify that the parameter of interest is $\beta$, the reaction of the short-term rate to the exchange rate. In the case of three regimes there are nine equations and ten unknown parameters, and it is enough only for partial identification. For each new regime indexed by the subscript $i=1,2,3$, the covariance matrix can be written as

$\Omega_{i}=\frac{1}{(1-\alpha \beta)^{2}}\left[\begin{array}{cc}(\beta+\gamma)^{2} \sigma_{i, z}^{2}+\beta^{2} \sigma_{i, \eta}^{2}+\sigma_{\varepsilon}^{2} & (1+\alpha \gamma)(\beta+\gamma) \sigma_{i, z}^{2}+\beta \sigma_{i, \eta}^{2}+\alpha \sigma_{\varepsilon}^{2} \\ \cdot & (1+\alpha \gamma)^{2} \sigma_{i, z}^{2}+\sigma_{i, \eta}^{2}+\alpha^{2} \sigma_{\varepsilon}^{2}\end{array}\right]$.

The parameter $\beta$ must solve the following system of equations (see the Appendix A for the full solution):

$\theta=\frac{\Delta \Omega_{21,12}-\Delta \Omega_{21,22}}{\Delta \Omega_{21,11}-\Delta \Omega_{21,12}}$

\footnotetext{
${ }^{4}$ In the macroeconomics literature, VARs are often estimated across samples that surely exhibit heteroscedasticity, without allowing shifts in parameters. Similarly, in the finance literature, many studies that even explicitly allow for variation in volatility, including GARCH models, often require that the parameters of the underlying equation are fixed (Rigobon and Sack, 2004).
} 


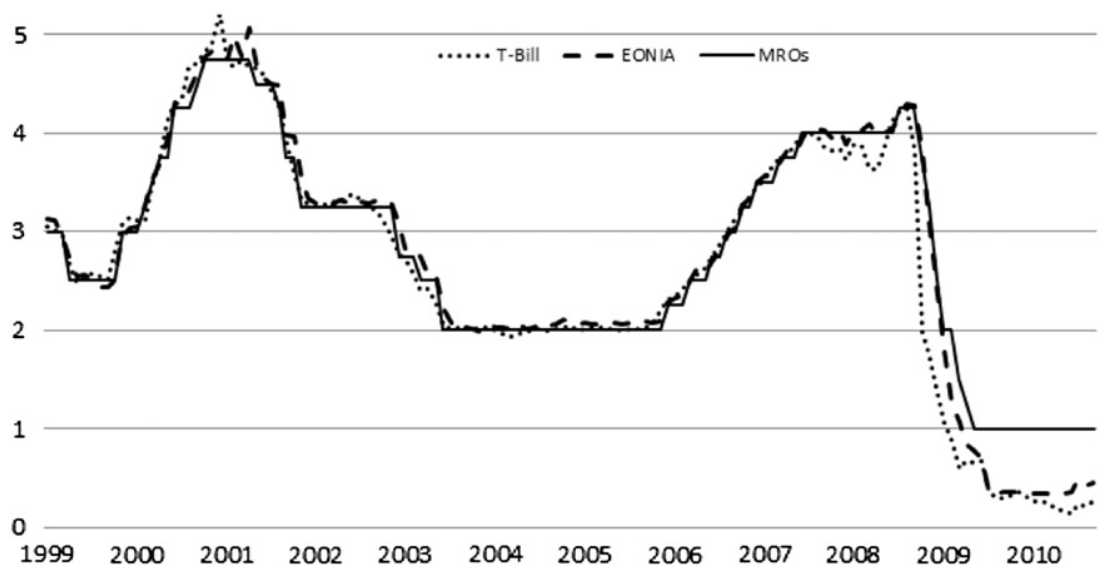

Fig. 2. T-Bill rate, EONIA and MROs.

$\theta=\frac{\Delta \Omega_{31,12}-\Delta \Omega_{31,22}}{\Delta \Omega_{31,11}-\Delta \Omega_{31,12}}$

where $\Delta \Omega_{j 1}=\Delta \Omega_{j} \Delta \Omega_{1}$ is the change in the covariance matrix from regime $j$ to regime 1 for $j=2,3 . \Delta \Omega_{j 1, k l}$ is the $k$ and $l$ element in matrix $j$.

When there are more than three regimes for the variance-covariance matrix, any three can be used to arrive at a solution to Eqs. (8) and (9). If the model is correctly specified, the estimates of $\beta$ should be the same for any three regimes. We implement the standard test of the overidentifying restrictions of the model. A rejection of the overidentifying restriction test implies that the homoscedastic policy shocks are violated or the parameters of equations are not stable across the regimes. Also, if the parameter $\beta$ is not constant the formulation of Rigobon and Sack (2003) may not capture the nonlinearity.

\section{Data and empirical evidence}

\subsection{Data}

In this study we use Germany's three-month Treasury bill rate as the short-term interest rate and euro-dollar exchange rate. Treasury bill rates (T-Bill) are not available for the European Central Bank. Therefore, we use the three-month T-Bill of Deutsche Bundesbank as the shortterm interest rate. One could argue that instead of the T-Bill, ECB interest rate on the main refinancing operations (MROs), or the Euro overnight index average (EONIA) would be more appropriate instruments for the short-term interest rate. A graph is plotted to show the relationship between three-month T-Bill rate of Germany, EONIA and MROs for 1999:1-2010:09 period. As shown in Fig. 2, the rates are very closely related and move together. Furthermore, descriptive statistics and correlations are calculated and reported in Table 1. The average of the MROs is slightly higher but less volatile than that of T-Bill and EONIA. The correlation between the T-Bill rate and MROs is approximately 0.97 while it became 0.99 in the pre-crisis period. The correlation between EONIA and MROs is also strong (0.99). A visual description and the results of correlations make it readily possible to verify that T-Bill rates may be used as a proxy for ECB policy action.

T-Bill is one of the most liquid securities at short maturities and it adjusts daily according to changes in expectation of monetary policy over the following term, while MROs are adjusted approximately once a month. ${ }^{5}$ The reason for using T-Bill rate instead of EONIA is that volatility in interest rates is an important factor for our identification approach and a relatively poor way to define heteroscedasticity of the shocks.

\footnotetext{
${ }^{5}$ Decisions on the euro area policy rates are taken during meetings of the Governing Council. 35 policy decisions were taken between 1999:01 and 2010:09.
}

Our empirical investigation relies on daily and monthly data covering the period from April 1999 to September 2010. The daily data are used for the following reasons. Firstly, the daily data allows us to define the heteroscedasticity of the shocks more accurately. Secondly, the liquidity in the money market rate can be affected by central banks on a daily basis. Lastly, T-Bills tend to anticipate monetary policy decisions; monetary policy can affect the daily movements of T-Bills even if policy rate decisions take place less often (Bohl et al., 2007).

In this framework, we assume that monetary policy shocks are homoscedastic. Therefore, the related sample stands for the non-policy dates (days immediately preceding the monetary policy committee meeting days) and the holidays and weekends are removed. Eurodollar exchange rates were obtained from the ECB website and Bundesbank staff provided the T-Bill rates.

The data are plotted in levels in Fig. 3. As can be seen in the graph, there is a negative relationship between the short term interest rate and the exchange rate.

\subsection{Estimates for widely used methodologies}

Formally, the dynamics of the short-term interest rates and the exchange rate are written as follows:

$\Delta i_{t}=\beta \Delta e_{t}+\varphi x_{t}+\varepsilon_{t}$

$\Delta e_{t}=\alpha \Delta i_{t}+\phi x_{t}+\eta_{t}$

where $i_{t}$ is the T-Bill rate, $e_{t}$ is the change exchange rate, $\varepsilon_{t}$ is the monetary policy shock, and $\eta_{t}$ is the exchange rate shock. As Rigobon and Sack (2003b) point out, control for observable macroeconomic shocks is required. We add lags in the exchange rate as an exogenous variable, as

Table 1

Descriptive statistics and correlations.

\begin{tabular}{llll}
\hline & EONIA & MROs & T-Bill \\
\hline Mean & 2.77 & 2.80 & 2.67 \\
Median & 2.79 & 2.75 & 2.71 \\
Maximum & 5.06 & 4.75 & 5.21 \\
Minimum & 0.34 & 1.00 & 0.13 \\
Std. dev. & 1.25 & 1.09 & 1.28 \\
Correlation & & MROs & T-Bill \\
\hline EONIA & EONIA & - & - \\
MROs & 1.00 & 1.00 & - \\
T-Bill & $0.99^{\mathrm{a}}$ & $0.97^{\mathrm{a}}$ & 1.00 \\
\hline
\end{tabular}

a Indicates significance at the $1 \%$ level. 


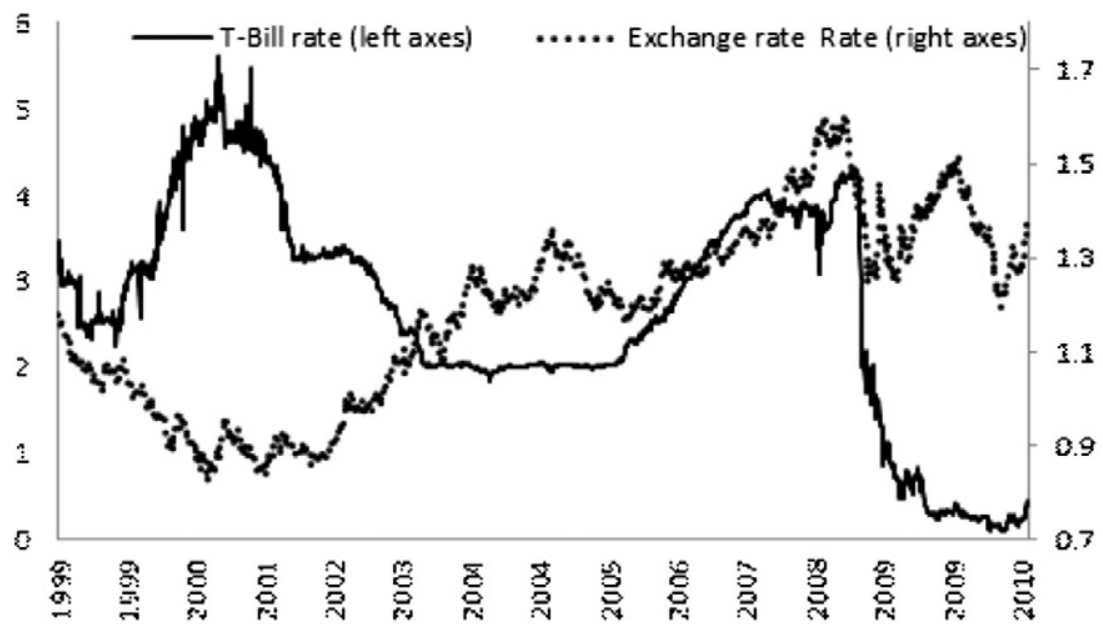

Fig. 3. T-Bill rate and exchange rate.

wells as lags in the short term interest rate. The variable $x_{t}$ is a vector containing 5 lags of the exchange rate and the interest rate.

As mentioned before, due to the endogeneity problem Eqs. (8) and (9) cannot be estimated and only reduced form of these equations can be estimated. We are interested in the impact of changes in the exchange rate on the short term interest rate. ECB policy reaction function can be estimated under inappropriate assumption of no simultaneous response of the exchange rate to the interest rate. The estimated results of the policy reaction function (Eq. (10)) are summarized in Table 2.

The changes in the exchange rate do not have a large impact on the interest rate. The estimated coefficient $(\beta)$ is insignificant and negative, which is consistent with ECB not being explicit about responding to a change in the exchange rate. In that case ignoring the endogeneity, heteroscedasticity and unobservability of common shock problems causes a strong biased estimated policy reaction.

In order to describe the movements in interest rates, a large literature has developed on estimating monetary policy rules. Monetary policy can be described by a rule based on contemporaneous inflation, output gap and lagged interest rate as follows:

$i_{t}=(1-\rho)\left(\beta_{0}+\beta_{y} y_{t}+\beta_{\pi} \pi_{t}\right)+\rho i_{t-1}$

where $\pi_{t}$ is the inflation rate, $y_{t}$ is the output gap, and $i_{t}$ is the policy rate. Consumer price inflation in the euro area is measured by the Harmonised Index of Consumer Prices (HICP). In line with e.g. Clarida et al. (1998), we take the industrial production index for the euro area and calculate the deviation of log output from its Hodrick-Prescott filter trend in order to identify the output gap. Table 2 shows the estimated parameters from this rule. This table indicates that the ECB does not respond to the variations in inflation, but responds significantly to the output gap. Because the exchange rate impacts on the path of output and inflation as discussed before, the rule needs to be modified to include information about the exchange rate. Suppose that exchange

Table 2

Response of daily changes in short-term interest rate to changes in exchange rate (ignoring endogeneity).

\begin{tabular}{llll}
\hline Variable & Coefficient & Std. error & t-Statistic \\
\hline Exchange rate & -0.13 & 0.08 & -1.50 \\
Sample: 1999 to 2010 & Included obs.: 2907 & \\
R-Squared: 0.20 & Durbin-Watson stat.: 2.00 & \\
S.D. dependent var.: 0.036 & S.E. of regression: 0.36 & \\
\hline
\end{tabular}

Regression includes a constant and five lags of the interest rate and exchange rate. The data are daily, and the sample runs from January 1999 to October 2010. rate, $e_{t}$, has been taken into account in formulating monetary policy as in:

$i_{t}=\gamma_{0}+\gamma_{y} y_{t}+\gamma_{\pi} \pi_{t}+\gamma_{e} \Delta e_{t}+\rho i_{t-1}$

where $\gamma_{0}=(1-\rho) \beta_{0}, \gamma_{y}=(1-\rho) \beta_{y}, \gamma_{\pi}=(1-\rho) \beta_{\pi}$ and $\gamma_{e}=$ $(1-\rho) \beta_{e}$. An estimate of the Eq. (13) using OLS indicates that the measured reaction of the interest rate to the variation in exchange rate is significant, and increases the output gap coefficient very slightly.

The empirical literature has adopted instrumental variables or VAR approaches to address the endogeneity problem arising from the contemporaneous regressors. Following Gerlach and Smets (2000), we use current inflation, current output gap, the lag of policy rates and exchange rates as instruments. The results in Table 3 show that the policy response to the exchange rate is positive but not significantly from zero. The results of IV estimation are sensitive to the choice of instrumental variables, and it is hard to find a suitable instrument which affects the exchange rate without affecting interest rates. Rigobon and Sack (2003) claims that using this sort of weak instruments leads to biased estimates. Lastly, we apply the structural VAR method to estimate a simultaneous four equations system using the output gap, inflation, the exchange rate and the policy rate. The structural VAR system is expressed as:

$A X_{T}=\Gamma X_{T-1}+u_{t}$

where $X_{t}^{\prime}=\left[y_{t}, \pi_{t}, e_{t} i_{t}\right]$ is stationary and structural error $u_{t} \sim$ i.i.d $N(0, D)$. Unfortunately this equation system cannot be estimated directly due to the identification issue. Additional information is required to identify the structural parameters and shocks. We impose restrictions on the contemporaneous matrix, $A$, following Cholesky decomposition and set matrix $D$ as diagonal. Matrix A becomes lower triangular and the system becomes just identified. ${ }^{6}$ The estimate results are presented in the last column of Table 3 . The results are essentially same as the instrumental variable estimation results. The response of the policy rate to the exchange rate is positive and insignificant.

The problem with Cholesky decomposition is that a triangular matrix A does not allow the contemporaneous relationship between exchange rate and interest rate. Traditional identification assumptions are used in the applied macroeconomics literature but are not appropriate in this context, because imposing restriction in one direction but not

\footnotetext{
${ }^{6}$ Cholesky decomposition assumes that shocks are propagated in the order of output gap, inflation, exchange rate and interest rate. In this ordering $y_{t}$ is only affected by its own shock; $\pi_{t}$ is affected contemporaneously by its own shocks and $y_{t}$ shocks; $e_{t}$ is affected by its own shocks, $y_{t}, \pi_{t}$ shocks; $i_{t}$ is affected by its own shocks and three other shocks.
} 
Table 3

Monetary policy rule.

\begin{tabular}{|c|c|c|c|c|}
\hline Coefficient & Without exchange rate (OLS) & Including exchange rate (OLS) & Including exchange rate (IV) & Including exchange rate (SVAR) \\
\hline$\gamma_{0}$ & $0.60(0.20)$ & $0.60(0.20)$ & $0.56(0.23)$ & $0.14(0.07)$ \\
\hline$\gamma_{y}$ & $0.09(0.02)$ & $0.10(0.03)$ & $0.09(0.02)$ & $0.05(0.01)$ \\
\hline$\gamma_{\pi}$ & $-0.14(0.09)$ & $-0.14(0.09)$ & $-0.12(0.11)$ & $0.07(0.04)$ \\
\hline$\gamma_{e}$ & - & $0.45(1.15)$ & $1.17(1.22)$ & $0.41(0.36)$ \\
\hline$\rho$ & $0.86(0.05)$ & $0.86(0.05)$ & & \\
\hline
\end{tabular}

Standard errors shown in parenthesis.

in the other is not realistic. ${ }^{7}$ Obvious long-run restrictions are not available to differentiate monetary policy shocks from exchange rate shocks.

Overall, applying commonly-used identification techniques or instrumental variables cannot effectively solve the endogeneity between interest rate and exchange rate or the omitted variable bias problem, as discussed before. In this paper, we use a relatively new methodology based on the heteroscedasticity of the error terms to identify the policy rate response to the exchange rate.

\subsection{Identification through heteroscedasticity estimates}

The initial step is determining the different regimes for the variancecovariance matrix of the reduced form shocks to monetary policy and the exchange rate. Firstly, Eq. (3) is estimated by VAR and computes the residuals. We define four regimes: one is that both interest rates and exchange rate shocks have high volatility, one is that both shocks have low volatility, and in the other two regimes in which one has low and the other has high volatility. Periods of high volatility are defined as when the thirty-day rolling variance of the residual from VAR is more than one standard deviation above its average as identified in Rigobon and Sack (2003). The four variance-covariance regimes are illustrated in Table 4.

Table 3 reveals that the covariance between the interest rate and exchange rate varies with shifts in their variances and it becomes negative when the volatility of exchange rate rises. These different regimes of the variance-covariance matrix are chosen arbitrarily. As described in previous sections, the monetary policy reaction to the exchange rate could be identified with at least three regimes. I treat Eqs. (8) and (9) as moment conditions and solve for the parameters using GMM. Estimates of the monetary policy reaction coefficient $\beta$ for daily and monthly data are listed in Table 5.

For the daily time series the results indicate a negative policy response to the exchange rate, with an estimated coefficient $\beta$ of -0.199 . By employing a more appropriate identification approach based on heteroscedasticity, a significant negative reaction of monetary policy to the exchange rate is found. This is the major result of the paper. The point estimate for the response coefficient $\beta$ shows that a 1 point rise in the exchange rate tends to decrease the three-month interest rate by around 20 basis points. Similar results are obtained when the other regimes are used to estimate the parameter. The estimates of monetary policy reactions resulting from other regimes are consistently low and close to one another.

In order to test whether the policy reaction to the exchange rate depends on the frequency of the data, we estimate the same system using lower frequency data. The results for monthly data, shown in Table 4, indicate that the estimated response of monetary policy is negative and larger than high frequency data. In addition, we consider a case of random 3-month rolling regimes instead of the thirty-day rolling regimes and the results are largely similar. Even so, the resulting estimates for low frequency and different identification regimes are still small in magnitude and support the hypothesis that the ECB does not react to exchange rate movements too much.

\footnotetext{
7 Short-run restrictions, long-run and sign restrictions are used in the literature to identify the VAR models.
}

There are four regimes and only three regimes are sufficient for identification, so the parameter is overidentified. Therefore, we also test whether the $\beta$ parameter is stable across different regimes and the homoscedasticity assumption of the policy shocks is valid. The result of the overidentification test shows that all assumptions of the heteroscedasticity based identification approach are valid. The hypothesis of parameter constancy cannot be rejected for both daily and monthly time series except in two cases (i.e. estimates under regimes $1,3,4$ for daily data and regimes $1,2,4$ for monthly data). ${ }^{8}$

There is a big debate among economists about the role of asset prices in the conduct of monetary policy. Cecchetti et al. (2000) find strong support for including stock prices in the central bank's policy rule. They argue that reacting to asset prices will allow central banks to stabilize inflation and output more successfully. In contrast Bernanke and Gertler (2001) claim that central banks should not react to asset prices, except insofar as they affect the expected inflation. In this regard Jean Claude Trichet (2002) said that " it is clearly not opportune to introduce asset prices into a monetary policy rule the central bank should commit to or in the central bank's reaction function." ${ }^{9}$ According to him, a wide range of economic and financial indicators (stock prices, housing prices, exchange rates) is also analyzed in depth and their assessment is made in the context of maintaining price stability over the medium term. The ECB does not react to their signals unless price stability is endangered. Trichet summarized that if monetary policy does not react directly to asset price developments, it clearly has to take into consideration all the consequences of these developments on the aggregate economy and expectations, since they may at some point affect price developments.

In line with this debate the empirical exercises of this paper are intended only to measure the policy response to the exchange rate. We are not primarily concerned with determining whether such a reaction is optimal. We find a significant, negative and small response of the policy reaction coefficient, although the primary objective of ECB is price stability and it is not explicit about responding to the exchange rate. But because the estimated policy reaction coefficient is within reasonable distance from the magnitude, it appears that the ECB responds to exchange rate movements only to offset the expected passing-through of exchange rate shocks to inflation and output. The empirical evidence of this paper supports that the ECB should monitor fluctuations in exchange rate rather than targeting.

\section{Conclusion}

Relatively little empirical evidence is available that estimates the impact of exchange rates on the conduct of monetary policy. Estimating the response of monetary policy to changes in the exchange rate is complicated by the endogeneity problem and the fact that both interest

\footnotetext{
${ }^{8}$ Many different overidentification tests could be performed and I have applied the GMM-overidentification test. The overidentifying restrictions are tested with the following test statistic: $\hat{q}=\bar{m}(\beta)^{\prime} V^{-1} \bar{m}(\beta)$ where $V^{-1}$ is the variance of the difference of the estimators. Note, however, that this approach does not test the assumption that the three shocks are uncorrelated. For a general treatment, see Harris and Matyas (1999) and Newey and McFadden (1994).

9 The full speech of Jean-Claude Trichet, governor of ECB from 2003 to 2011, is available at http://www.bis.org/review/r020426a.pdf.
} 
Table 4

Variance-covariance matrix of regimes.

\begin{tabular}{lllr}
\hline & Variance of monetary policy & Variance of exchange rate & Covariance \\
\hline Daily data & & & \\
Regime 1 & 0.001209 & $\mathbf{0 . 0 0 0 1 2 3}$ & -0.000007 \\
Regime 2 & 0.000082 & 0.000014 & 0.000001 \\
Regime 3 & $\mathbf{0 . 0 0 2 2 7 6}$ & $\mathbf{0 . 0 0 0 0 6 6}$ & -0.000067 \\
Regime 4 & $\mathbf{0 . 0 1 0 1 1 3}$ & 0.000053 & 0.000161 \\
Monthly data & & \\
Regime 1 & 0.002135 & $\mathbf{0 . 0 0 0 0 8 7}$ & -0.000088 \\
Regime 2 & 0.000488 & 0.000017 & 0.000009 \\
Regime 3 & $\mathbf{0 . 0 0 2 1 7 1}$ & $\mathbf{0 . 0 0 0 0 7 4}$ & -0.000106 \\
Regime 4 & $\mathbf{0 . 0 0 7 6 5 7}$ & 0.000043 & 0.000024 \\
\hline
\end{tabular}

High variance regimes are in bold.

rates and the exchange rate react to many other variables. This paper provides new empirical findings on the impact of exchange rate movements on interest rates using daily and monthly data from the ECB between 1999 and 2010.

Using the method of identification through heteroscedasticity developed by Rigobon (2003a), the reaction of policy to the exchange rate can be measured effectively when there are shifts in the variance of exchange rate shocks. This methodology takes into account the simultaneous response of both the interest rate and exchange rate to each other and common factors affecting both variables which widely used approaches in the literature might not be addressed.

The empirical results indicate that monetary policy reacts significantly to changes in the exchange rate, with a 1 point rise (fall) in the exchange rate increasing the interest rate by 20 basis points. For daily and monthly time series, the exchange rate has a negative but small impact on the interest rate of ECB between 1999 and 2010. Such a significant but small policy reaction coefficient implies that ECB consider the fluctuations in exchange rate but not to target them. This is consistent with the suggestion that central banks may respond to the movements in asset prices only to the extent that they impact on the macroeconomy, since the exchange rate affects the expected inflation and output path as Taylor (2001) suggests.

\section{Appendix A. Details on methodology}

In the present Appendix A, we provide the solution to the identification problem mention in Section 3 and show how parameter $\beta$ solves the system when at least three different regimes are given. that

Define $\Delta \Omega_{21}=\Delta \Omega_{2}-\Delta \Omega_{1}$ and $\Delta \Omega_{31}=\Delta \Omega_{3}-\Delta \Omega_{1}$. Eq. (7) implies

$\Omega_{j 1}=\frac{1}{(1-\alpha \beta)^{2}}\left[\begin{array}{cc}(\beta+\gamma)^{2} \Delta \sigma_{j 1, z}^{2}+\beta^{2} \Delta \sigma_{j 1, \eta}^{2} & (1+\alpha \gamma)(\beta+\gamma) \Delta \sigma_{j 1, z}^{2}+\beta \Delta \sigma_{j 1, \eta}^{2} \\ \cdot & (1+\alpha \gamma)^{2} \Delta \sigma_{j 1, z}^{2}+\Delta \sigma_{j 1, \eta}^{2}\end{array}\right]$

where $\Delta \sigma_{j 1, z}^{2}=\Delta \sigma_{j, z}^{2}-\Delta \sigma_{1, z}^{2}$ and $\Delta \sigma_{j 1, \eta}^{2}=\Delta \sigma_{j, \eta}^{2}-\Delta \sigma_{1, \eta}^{2}$ for $j=\{2,3\}$. Since the $\sigma_{\varepsilon}^{2}$ is homoscedastic and $\alpha, \beta$ and $\gamma$ parameters are stable, the change in covariance matrix does not depend on the variance of monetary policy shocks. These two changes in the covariance matrices, $\Delta \Omega_{21}$ and $\Delta \Omega_{31}$, form a system of six nonlinear equations with seven

Table 5

Estimates of ECB's reaction to exchange rate under alternative regimes.

\begin{tabular}{lrrrc}
\hline & Regimes 1, 2, 3 & Regimes 1, 2, 4 & Regimes 1, 3, 4 & Regimes 2, 3, 4 \\
\hline Daily data & & & & \\
Coefficient & -0.19999 & -0.27327 & -0.27117 & -0.15588 \\
Std. deviation & 0.00901 & 0.00615 & 0.02328 & 0.01639 \\
& & & & \\
Monthly data & & & & \\
Coefficient & -0.32621 & -0.29742 & -0.51676 & -0.28575 \\
Std. deviation & 0.00014 & 0.00113 & 0.02471 & 0.00007 \\
\hline
\end{tabular}

unknowns, but in which $\beta$ is just identified. To see this, rewrite the covariance matrix as:

$$
\Omega_{j 1}=\frac{1}{(1-\alpha \beta)^{2}}\left[\begin{array}{cc}
\omega_{z, j}+\beta^{2} \Delta \sigma_{j 1, \eta}^{2} & \theta \omega_{z, 2}+\beta \Delta \sigma_{j 1, \eta}^{2} \\
\theta^{2} \omega_{z, 2}+\Delta \sigma_{j 1, \eta}^{2}
\end{array}\right] \theta=\frac{1+\alpha \gamma}{\beta+\gamma} \omega_{z, j}=(\beta+\gamma)^{2} \Delta \sigma_{j 1, z}^{2} .
$$

The six equations that result can be written as follows:

$\omega_{z, 2}+\beta^{2} \Delta \sigma_{21, \eta}^{2}=(1-\alpha \beta)^{2} \cdot \Delta \Omega_{21,11}$

$\theta \omega_{z, 2}+\beta \Delta \sigma_{21, \eta}^{2}=(1-\alpha \beta)^{2} \cdot \Delta \Omega_{21,12}$

$\theta^{2} \omega_{z, 2}+\Delta \sigma_{21, \eta}^{2}=(1-\alpha \beta)^{2} \cdot \Delta \Omega_{21,22}$

$\omega_{z, 3}+\beta^{2} \Delta \sigma_{31, \eta}^{2}=(1-\alpha \beta)^{2} \cdot \Delta \Omega_{31,11}$

$\theta \omega_{z, 3}+\beta \Delta \sigma_{31, \eta}^{2}=(1-\alpha \beta)^{2} \cdot \Delta \Omega_{31,12}$

$\theta^{2} \omega_{z, 3}+\Delta \sigma_{31, \eta}^{2}=(1-\alpha \beta)^{2} \cdot \Delta \Omega_{31,22}$

where $\Delta \Omega_{j 1, k l}$ is the $k$ and $l$ element of the $j$ matrix. If $\theta \beta \neq 1$, which assures finite variance, then the three equations for each covariance matrix collapse to

$\theta=\frac{\Delta \Omega_{21,12}-\Delta \Omega_{21,22}}{\Delta \Omega_{21,11}-\Delta \Omega_{21,12}}$

$\theta=\frac{\Delta \Omega_{31,12}-\Delta \Omega_{31,22}}{\Delta \Omega_{31,11}-\Delta \Omega_{31,12}}$

which is a system of two equations with two unknowns $(\theta, \beta)$. Solving this system of Eqs. (8) and (9), the parameter of interest $\beta$, and estimate for combining $\theta$ are obtained. Rigobon and Sack (2003) selection criteria which are also applied in this study are as follows: if the two roots have different signs, they select the positive one. If they have the same sign, they choose the smaller in absolute value. Substitute the Eq. (8) in Eq. (9) below the quadratic equation obtained in terms of $\beta$

$a \beta^{2}+b \beta+c=0$

where

$a=\Delta \Omega_{31,22} \Delta \Omega_{21,12}-\Delta \Omega_{21,22} \Delta \Omega_{31,12}$

$b=\Delta \Omega_{31,22} \Delta \Omega_{21,11}-\Delta \Omega_{21,22} \Delta \Omega_{31,11}$

$c=\Delta \Omega_{31,12} \Delta \Omega_{21,11}-\Delta \Omega_{21,12} \Delta \Omega_{31,11}$.

The quadratic equation has a real solution and after some algebra it can be written as follows:

$(1+\alpha \gamma) d \beta^{2}-(2 \beta+\alpha \gamma \beta+\gamma) d \beta+\beta(\beta+\gamma) d$

where

$d=\sigma_{z, 3}^{2} \sigma_{\eta, 2}^{2}-\sigma_{z, 3}^{2} \sigma_{\eta, 1}^{2}-\sigma_{z, 1}^{2} \sigma_{\eta, 2}^{2}-\sigma_{z, 2}^{2} \sigma_{\eta, 3}^{2}+\sigma_{z, 1}^{2} \sigma_{\eta, 3}^{2}+\sigma_{z, 2}^{2}$

On condition that $d \neq 0$, the equation has two solutions:

$\beta_{1}=\beta$

$\beta_{2}=\frac{\beta+\gamma}{\alpha \gamma+1}=\frac{1}{\theta}$

Hence, we are able to estimate consistently $\beta$ as long as we choose the right solution of the quadratic form and we have at least three regimes for the covariance matrix.

\section{References}

Ball, L., 1999. Policy Rules for Open Economies. In: Taylor, John B. (Ed.), Monetary Policy Rules. University of Chicago Press, Chicago.

Ball, L., 2002. Policy Rules and External Shocks. Working Papers Central Bank of Chile, 82. Central Bank of Chile.

Bernanke, B., Gertler, M., 1999. Monetary policy and asset price volatility. Federal Reserve Bank of Kansas City. Econ. Rev. LXXXIV, 17-51. 
Bernanke, B., Gertler, M., 2001. Should central banks respond to movements in asset prices? Am. Econ. Rev. Pap. Proc. XCI, 253-257.

Bohl, Martin T., Siklos, P.L., Werner, T., 2007. Do central banks react to the stock market? The case of the Bundesbank. J. Bank. Financ. 31, 719-733.

Cecchetti, S., Genberg, H., Lipsky, J., Wadhwani, S., 2000. Asset Prices and Central Bank Policy. International Center for Monetary and Banking Studies, London.

Clarida, R., Gali, J., Gertler, M., 1998. Monetary policy rules in practice: some international evidence. Eur. Econ. Rev. 42, 1033-1067.

Filosa, R., 2001. Monetary policy rules in some mature emerging economies. BIS Pap. 8, 39-68.

Frömmel, M., Schobert, F., 2006. Monetary Policy Rules in Central and Eastern Europe. Discussion paper. Hannover University, p. 341.

Gerlach, S., Smets, F., 2000. MCIs and Monetary Policy. European Economic Review, Vol. 44(9). Elsevier, pp. 1677-1700 (October).

Harris, D., Matyas, L., 1999. Introduction to the Generalized Method of Moments Estimation. In: Matyas, L. (Ed.), Generalized Method of Moments Estimation. Cambridge University Press, Cambridge.

Mohanty, M.S., Klau, M., 2005. Monetary Policy Rules in Emerging Market Economies: Issues and Evidence. In: Rolf, J., Vinhas de Souza, Lucio, Langhammer, Rolf J. (Eds.), Monetary Policy and Macroeconomic Stabilization in Latin America. The Kiel Institute.

Newey, W., McFadden, D., 1994. Large Sample Estimation and Hypothesis Testing. In: Engle, R., McFadden, D. (Eds.), Handbook of Econometrics. IV, pp. 2113-2247.
Osawa, Naoto, 2006. Monetary Policy Responses to the Exchange Rate: Empirical Evidence from Three East Asian Inflation-targeting Countries. Bank of Japan Working Papers Series.

Rigobon, R., 2003. Identification through heteroscedasticity. Rev. Econ. Stat. 85, 777-792.

Rigobon, R., Sack, B., 2003. Measuring the reaction of monetary policy to the stock market. Q. J. Econ. 118, 639-669.

Rigobon, R., Sack, B., 2004. The impact of monetary policy on asset prices. J. Monet. Econ. $51,1553-1575$.

Sek, Siok Kun, 2008. "Interactions between Monetary Policy and Exchange Rate in Inflation Targeting Emerging Countries: The Case of Three East Asian countries," MPRA Paper 12034. University Library of Munich, Germany.

Taylor, J., 2001. The role of the exchange rate in monetary policy rules. Am. Econ. Rev. 91, 263-267.

Taylor, J., 2002. The Monetary Transmission Mechanism and the Evaluation of Monetary Policy Rules, First ed. Central Banking, Analysis, and Economic Policies Book Series, Monetary Policy: Rules and Transmission Mechanisms, 4, pp. 21-46.

Trichet, J.C., 2002. "Asset price bubbles and their implications for monetary policy and financial stability", Keynote address, Asset Price Bubbles conference held at the Federal Reserve Bank of Chicago, 23 April 2002. Central Bank Articles and Speeches. 